\title{
"De olho no que pisa": os perigos da contaminação do solo*
}

\section{"Watch your step": dangers of soil contamination}

Flavio Manoel Rodrigues da Silva Júnior

Universidade Federal do Rio Grande, Instituto de Ciências Biológicas, Rio Grande, Rio Grande do Sul, Brasil

É indiscutível que, dado o volume de água no nosso planeta, esse poderia ser chamado de Planeta Água. No entanto, não podemos fechar os olhos para os quase $30 \%$ de superfície terrestre que dá nome ao planeta, que abriga os mais de 7,5 bilhões de seres humanos e uma importante parcela de nossa biodiversidade. É sobre nosso chão, sobre nosso solo, que estão edificadas nossas construções, rodovias, ferrovias; é nele que se cultiva ou se cria a maior parte dos alimentos para nosso consumo; e onde passamos a maior parte das nossas vidas.

O compartimento solo está sujeito a diferentes processos que podem reduzir sua qualidade, tais como erosão, desertificação, inundação, presença de patógenos e parasitas e a contaminação por substâncias químicas. Todos esses processos parecem ter estreita relação com atividades antropogênicas; mas, por outro lado, também são capazes de afetar negativamente a qualidade de vida do ser humano. Dentre esses, destaca-se a contaminação química do solo, não porque é o mais agressivo ou o que causa maiores prejuízos ao solo, mas porque é o mais silencioso e invisível. Certamente uma mãe impediria seu filho de brincar na areia para "não pegar" vermes, germes, bactérias, bicho de pé; jamais para evitar plumbemia, selenose ou intoxicação por qualquer outro elemento químico, que pode estar presente em altas concentrações no solo.

Embora o solo seja fonte e/ou depósito de muitos contaminantes químicos, o número de estudos que investigam a amplitude da contaminação dos solos e dos seus efeitos ecológicos e na saúde humana ainda é bem inferior ao daqueles sobre a contaminação do ambiente aquático, por exemplo. Qualquer um pode chegar à mesma conclusão realizando uma busca simples em alguma base de dados de artigos científicos utilizando os termos indexadores correspondentes ao assunto.
Sob o ponto de vista da proteção legal dos compartimentos ambientais e tomando como base as resoluções do Conselho Nacional do Meio Ambiente (CONAMA), embora a Resolução No 420/2009', referente à proteção da qualidade do solo e das águas subterrâneas, seja infinitamente mais moderna que a Resolução $N^{\circ}$ 003/1990², que dispõe sobre qualidade do ar (registre-se aqui a necessidade urgente de atualizar essa última Resolução), ela possui alguns gargalos de exequibilidade. Talvez o principal deles seja o estabelecimento dos valores de referência de qualidade (VRQs) por meio dos órgãos ambientais estaduais e do Distrito Federal.

$\mathrm{Na}$ Resolução CONAMA No 420/2009', a indicação de quais solos seguirão as diretrizes para - gerenciamento de áreas contaminadas se dá por meio da categorização dos solos em diferentes classes de qualidade do solo, baseada na concentração de substâncias químicas, estabelecendo quatro classes em ordem crescente de contaminação: Classe 1, Classe 2, Classe 3 e Classe 4 . Esse enquadramento é realizado com base em valores orientadores: os VRQs; os de prevenção (VP); e os de investigação (VI). O VI é a concentração de uma determinada substância no solo que, em níveis elevados, apresenta riscos potenciais à saúde humana. O VP é o valor limite de uma determinada substância, de modo que seja capaz de sustentar as suas funções principais e foi estabelecido baseado em análise de fitotoxicidade e avaliação de risco ecológico. $E$ O $V R Q$ é a concentração de uma determinada substância que define a qualidade natural do solo. Os dois primeiros valores foram determinados na referida Resolução; mas os VRQs seriam estabelecidos pelos órgãos ambientais estaduais e do Distrito Federal competentes em um prazo originalmente de quatro anos após publicada aquela Resolução; posteriormente, ficou estabelecido um novo prazo máximo, dezembro de 2014. Até 2016, dentre

\footnotetext{
* Artigo de opinião escrito por Palestrante do II Encontro Científico Internacional do Instituto Evandro Chagas, com realização no período de 25 a 27 de outubro de 2017, em Ananindeua, Pará, Brasil. Todos os artigos dessa modalidade foram analisados pela Comissão Científica do Evento e, posteriormente, pelos Editores da RPAS.
}

\section{Correspondência / Correspondence:}

Flavio Manoel Rodrigues da Silva Júnior

Universidade Federal do Rio Grande, Instituto de Ciências Biológicas

Av. Itália km 8. Campus Carreiros - CEP: 96203-900 - Rio Grande, Rio Grande do Sul, Brasil - Tel.: +55 (53) $3233-6633$

E-mail: f.m.r.silvajunior@gmail.com 
todos os órgãos ambientais estaduais e do Distrito Federal, apenas cinco haviam estabelecido os VRQs próprios $^{3}$. Mesmo para esses Estados, o número de substâncias químicas contempladas é reduzido.

Saindo da esfera legal, convém ressaltar outros aspectos sobre a exposição aos solos e seus contaminantes químicos, bem como seus efeitos adversos aos organismos vivos. $\bigcirc$ primeiro dado relevante a ser mencionado, e que pouca gente conhece, é que a United States Environmental Protection Agency estima a taxa de ingestão involuntária de solo (solos + poeira) na ordem de: 100 mg/dia, para crianças de 0 a 6 meses de idade; 200 mg/dia, para crianças de 6 meses até 12 anos de idade; e de $100 \mathrm{mg} /$ dia, para indivíduos a partir de 12 anos de idade ${ }^{4}$. Em uma conta rápida, considerando uma expectativa de vida de aproximadamente 80 anos, calculamos que cada ser humano ingere, involuntariamente, quase $3,5 \mathrm{~kg}$ de solo durante sua vida. Isso quer dizer que, hipoteticamente, uma pessoa que passa a vida toda em um solo com uma concentração de $300 \mathrm{mg} / \mathrm{kg}$ de chumbo (permitida pela Resolução CONAMA para solos residenciais) ingere, de forma involuntária, só por viver e respirar naquele ambiente, mais de $1 \mathrm{~g}$ de chumbo ao longo da vida. Parece pouco? Isso equivale, em média, a 34,3 $\mu \mathrm{g} /$ dia de chumbo. Aqui cabe mencionar que a Food and Drug Administration, agência americana responsável pelo controle da segurança alimentar, fixa em $6 \mu \mathrm{g} /$ dia o nível máximo de ingestão de chumbo por via alimentar ${ }^{5}$.

Em 2014, publicamos um estudo que relacionava a ingestão de solo de áreas impactadas por atividades de carvão com o risco mutagênico obtido por meio do consagrado teste de Ames ${ }^{6}$. Para isso, foi calculado o volume de solo necessário para dobrar a taxa de mutação espontânea e o tempo necessário para que essa taxa fosse atingida (utilizando o valor de $200 \mathrm{mg} /$ dia de ingestão involuntária de solo em crianças). Os resultados revelaram que a exposição aos solos, por um período entre 0,6-3 dias, já era suficiente para dobrar a taxa de mutação espontânea, uma vez que essas taxas foram obtidas com valores que variaram entre 129,3 e $600 \mathrm{mg}$ de solo. Entre as áreas de coleta de solo desse estudo estavam parques públicos, o que liga um alerta sobre o risco mutagênico ao qual as crianças podem estar expostas, pelo simples e inocente fato de brincar em um parque ou em uma praça próximos à sua casa.

Outro estudo investigou, experimentalmente, os impactos da exposição a solos de praças públicas contaminados por mercúrio. Durante 120 dias, ratos Wistar foram expostos oralmente ao lixiviado dos solos e, após esse período, foram constatadas alterações hematológicas, fisiológicas e principalmente comportamentais. Após essa exposição crônica, alguns ratos começaram a perder a mobilidade do tronco posterior, comprometendo a locomoção dos mesmos. Obviamente, tal resultado não pode ser extrapolado para um cenário de exposição humana a esses solos, mas serve de alerta para o perigo de uma exposição crônica a solos urbanos contaminados por mercúrio ${ }^{7}$.

Uma série de outros estudos experimentais tem revelado efeitos adversos decorrentes da exposição a solos urbanos contaminados, causando prejuízos genéticos $^{8}$, fisiológicos ${ }^{9}$ e reprodutivos ${ }^{10}$. Como mencionado anteriormente, devemos ter cuidado na extrapolação desses cenários, mas tais estudos servem para revelar os perigos da exposição a solos contaminados por substâncias químicas e para que tenhamos mais cuidado onde pisamos.

Nossa estreita relação com o solo realça a necessidade do cuidado para com esse compartimento ambiental, e os estudos mencionados nos alertam para a diminuição progressiva da qualidade do solo e para os potenciais riscos invisíveis, aos quais estamos vulneráveis. Os órgãos ambientais competentes precisam fazer com que sejam cumpridos os deveres legais dos poluidores e aprimorar, a cada dia, os mecanismos que dispomos para a manutenção da qualidade ambiental. De modo mais amplo, a sociedade como um todo precisa estar bem atenta, pois, ao que parece, "o que polvi é invisível aos olhos".

\section{REFERÊNCIAS}

1 Brasil. Ministério do Meio Ambiente. Conselho Nacional do Meio Ambiente. Resolução No 420, de 28 de dezembro de 2009. Dispõe sobre critérios e valores orientadores de qualidade do solo quanto à presença de substâncias químicas e estabelece diretrizes para o gerenciamento ambiental de áreas contaminadas por essas substâncias em decorrência de atividades antrópicas. Diário Oficial da União, Brasília (DF), 2009 dez 30; Seção 1:81-4.

2 Brasil. Ministério do Meio Ambiente. Conselho Nacional do Meio Ambiente. Resolução No 003, de 28 de junho de 1990. Dispõe sobre padrões de qualidade do ar, previstos no PRONAR. Diário Oficial da União, Brasília (DF), 1990 ago 22; Seção $1: 15937-9$.

3 Reis FO, Martinez EA, Silva Júnior FMR, Lima ACR. Análise dos dispositivos legais nos estados brasileiros perante a Resolução 420/2009. Âmbito Jurídico, Rio Grande [Internet]. 2017 mar [citado 2017 out 13];XX(158). Disponível em: http:// ambito-juridico.com.br/site/?n_link=revista_artigos leitura\&artigo_id $=18630$.

4 U.S. Environmental Protection Agency. Office of Research and Development. Update for chapter 5 of the Exposure Factors Handbook: Soil and Dust Ingestion. Washington: United States Environmental Protection Agency; 2017. (EPA/600/R-17/384F). 
5 U.S. Department of Health and Human Services. U.S. Food \& Drug Administration. Questions and answers on lead in foods [Internet]. Silver Spring (MD): U.S. Food \& Drug Administration; 2017 [cited 2017 Oct 14]. Available from: https://www. fda.gov/Food/FoodbornelllnessContaminants/ Metals/ucm557424.htm.

6 Silva Júnior FMR, Vargas VMF. Tools used to estimate soil quality in coal combustion waste areas. An Acad Bras Cienc. 2014 Jun;86(2): 769-76.

7 Muccillo-Baisch AL, Mirlean N, Carrazzoni D, Soares MCF, Goulart GP, Baisch P. Health effects of ingestion of mercury-polluted urban soil: an animal experiment. Environ Geochem Health. 2012 Feb;34(1):43-53.
8 Garcia EM, Silva Junior FMR, Tavella RA, Cruz CG, Baisch PRM, Muccillo-Baisch AL. Genotoxicity in the offspring of rats exposed to contaminated and acidified experimentally soils. Water Air Soil Pollut. 2017 Jul;228:254.

9 Silva Júnior FMR, Silva PF, Garcia EM, Klein RD, Peraza-Cardoso G, Baisch PR, et al. Toxic effects of the ingestion of water-soluble elements found in soil under the atmospheric influence of an industrial complex. Environ Geochem Health. 2013 Jun;35(3):317-31.

10 Garcia EM, Silva Junior FMR, Soares MCF, Muccillo-Baisch AL. Developmental effects of parental exposure to soil contaminated with urban metals. Sci Total Environ. 2015 Jul;520: 206-12. 